\title{
MUTUAL SHAPING BETWEEN TECHNOLOGIES AND LAW: MEMORIES OF NORWEGIAN E-HEALTH INFRASTRUCTURES
}

\author{
A.A. ZAYTSEVA \\ Department of Informatics, University of Oslo, Norway.
}

\section{ABSTRACT}

This work suggests a method to study mutual shaping between technologies and law drawing on empirical evidence from two different and simultaneously developing patient-oriented information systems in e-health. The approach of Complex Adaptive Systems is applied to analyze documentary data in the first case to identify causal elements in the 'memory' of its design work, and the narrative data in situ and ex situ - for subsequent tracing of attractions in the legal environment. A hypothesis on whether both case studies share the same attractions is generated for further testing in the second case. Having replicated the method, the researcher provides explanations regarding the studied phenomenon based on empirical material of the Norwegian e-health sector. Keywords: attraction, design work, information systems, law, memory, mutual shaping.

\section{INTRODUCTION}

The research is aimed at providing a solution on how to study mutual shaping between technologies and law by use of Complex Adaptive Systems (CAS) approach and narrative analysis. Transdisciplinarity of the research is enhanced by considering design studies of information systems (IS) and the legal research. Two contrasting cases of information technologies within the Norwegian e-health context are selected. One technology is a private solution for storing and sharing health data among health personnel by patients, whereas the second case is a nationwide public sector information infrastructure for critical health data processing in emergency situations. Although these technologies have different legal grounds designwise - one being private and the other public - both are so-called 'patient-oriented' technologies, which implies their similarity. These technologies imply high involvement of patients in the decision-making process during their treatment, which is a challenging issue for the Norwegian legislators to ensure. As of 2015, Norway still follows the technology-specific legal approach [1] that makes legislation co-evolve [2] with the emerging technologies tightly and simultaneously.

In the Complex Systems Science has emerged an interest to study peculiarities of the legal realm, e.g. the resilience of the European supranational legislation to changes [3], where networks of legal normative acts of varied statuses in hierarchy have been studied in nodes and links to each other based on quantitative modeling. Playing with nodes enabled the researchers to make conclusions about patterns of responsiveness of the European legislation to emerging social issues. However, the mentioned research is limited only within the legal area of interest and regulative focus, as in the legal discipline. In design studies of IS, which tend to imply qualitative bottom-up methodologies, another problem has been observed, particularly the lack of 'theoretical frameworks for the big picture of the relationship between IS and law', because research in the IS field is basically bounded with organizational focus only [4].

The logic at the edge in Complexity Science [5] inspires the will to overcome organizational boundaries of the IS studies and regulatory focus of the legal research for the deeper insight into pure techno-legal dimension at the edge of the disciplines and cross-over cases. 


\section{EMPIRICAL SETTING AND METHODOLOGICAL PRECONDITIONS}

Since the beginning of the new century, Norway has been concerned with improvements in the e-health sector. Priorities that have been highlighted include adequate medical service to residents, ensuring privacy and human dignity of patients, increasing information flow among the healthcare institutions and teams, and involving the patients in the treatment processes. The legislation in e-health co-evolves with the policies taken and consists of two main regulatory levels - laws and bylaws. The laws become more specialized year by year, but they have norms excluding their power in some rare cases, which private technologies use to regulate their activities in agreements.

The case study, which is used in the given research to generate a method for studying mutual shaping between technologies and law, is a private IT solution, which is hereafter called 'HealthBook'. According to its concept, personal health information is uploaded and archived by its owners - usual individuals - and is shared by them for private purposes with the treating health personnel or anyone else. The technology employs a web-based interface for reading, uploading, and deleting this health information, and a server and a smartphone application that exploits camera for the data upload. The design work on HealthBook began in October 2011 and partially ended in June 2013 with a finished prototype. The design process might proceed in 2015. Specificity of this technology lies in its provision of data sharing from patient to healthcare and not vice versa which is typical for the public e-health infrastructures.

The second case study is a public sector IT solution for collecting vital health data for use by health personnel exercising healthcare cross-over organizational boundaries in situations threatening patient's life. Usual individuals can access their health data via the official health portal. The described information system is hereafter called the National Core Journal. Public discussions to develop such a system started in 2007 and preparation to the design work began simultaneously. The National Core Journal is supposed to be fully realized by 2017 in Oslo. As of 2015, this information system has been implemented as a pilot project in a couple of regions in Norway. The technology has been generally regulated by the Act on Health Registries since June 2012 and by an own bylaw on the National Core Journal since May 2013.

In this research, the design process, or 'design work', is defined as a CAS with 'constrained release of energy' [6] of the involved people making a technologic device from scattered technical elements (e.g. formats, platforms, encryption methods, etc.) [7], which are nested within the national legal environment that has its own elements of formal norms and conventional values (e.g. concrete paragraphs and articles in laws, and legally matter values on technologies inspired of design practices) in dynamic interaction with the former in a particular time. Having been inspired by the school on CAS of the Santa Fe Institute, the researcher assumes that the 'design work' has a 'memory' defined as 'retained parts of the input history' [8]. If the researcher assumes that a CAS of a design work in a case study has an own memory, then it is possible to assume that the design work has a memory bank [9], which is found in shared documentation - reports from the design meetings or with external experts, versions of technical specifications, available e-mail communication, legal proposals and opinion letters, etc. that help people to refer to their earlier talks wherein something particular was discussed.

Generation of the method and its replication has been conducted while analyzing documentary data from the design works on the technologies: 50 documents for the first case study and 120 documents for the second one. From the texts, syntactical elements relevant either to technology or law as their smallest particles have been deduced, but interpretation of the elements is neither broad nor specific. Kinds of people ever involved in the design work are also coded for the visual representations. On the drafted visual representation of the memory for design work in the first case, the researcher investigates visible complex networks of argumentation - 'events'. As a result, only few elements from their total amount are called causal elements of the design work due to the fact that 
they collect most of the links in the stepwise argumentation-based reduction of the 'events'. Although these elements cannot possess the whole contextual richness [10], they indicate topics in the memory, which deserve narrative clarification. Ten interviews have been collected. The narrative acts, or interview data in situ from people of the design work and ex situ with the external experts also being involved, serve as material for retrieval of additional, specific information from the individual experts. It helps to find possible attractions in law from the identified causal elements. Whether the respective attractions are shared between the cases is subsequently investigated within the method.

\section{ANALYSIS, METHOD GENERATION, AND STEPWISE RESULTS}

In order to draft a visual representation of memory for the first case study - HealthBook - the elements of technology and law have been manually extracted from the available documents relevant to the design work. These documents were originally written in Norwegian (Fig. 1).

As a result, 51 technological elements were collected and placed at the top sector of the memory, 16 elements of persons in the design work were placed in the middle sector, and 23 legal elements were placed at the bottom sector (Fig. 2).

The earliest mentioned phrase with the element provides it with a time-tag of when it was introduced for the first time. Having been mentioned once in the text, an element gets its own 'track' in the memory and subsequent time-tags corresponding to the dates of the documents when the element appears. Authorship of the element is designated with a color. When mentioned again by any other person of the design work besides the original author, the element re-appears in the track and gets colored correspondingly. Afterward, links are built among the elements based on authentic argumentation as in the text: naming one after another as a suggestion, introducing one in the form of question or in negation, etc. Visual representations are handy for illustration of complex phenomena [11]. So, in Fig. 2, we notice seven complex networks, or 'events', with elements having their node degrees of three or more. These seven complex networks deserve a closer look. They are highlighted in Fig. 3.

Thus, from the visual representation of the memory with 'events' (Fig. 3), the researcher retrieves elements composing each 'event' (Fig. 4). For clarity, the elements that belong to specific 'events' have been colored to indicate where they have been extracted from in Fig. 3.

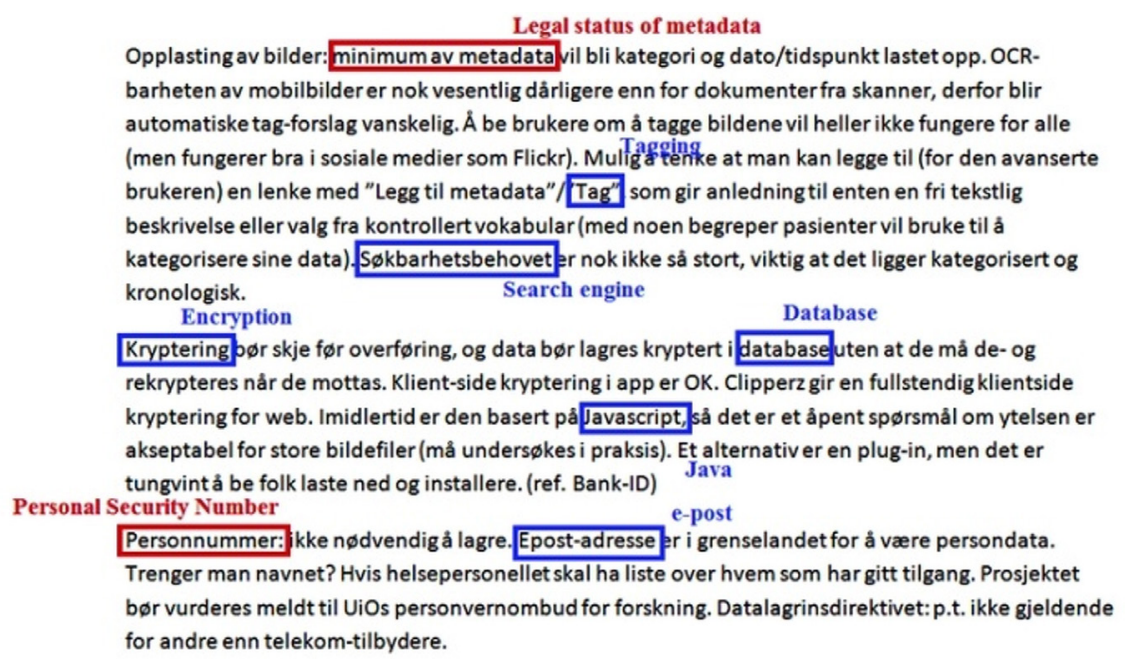

Figure 1: Extracting elements of memory from the documentary data. 


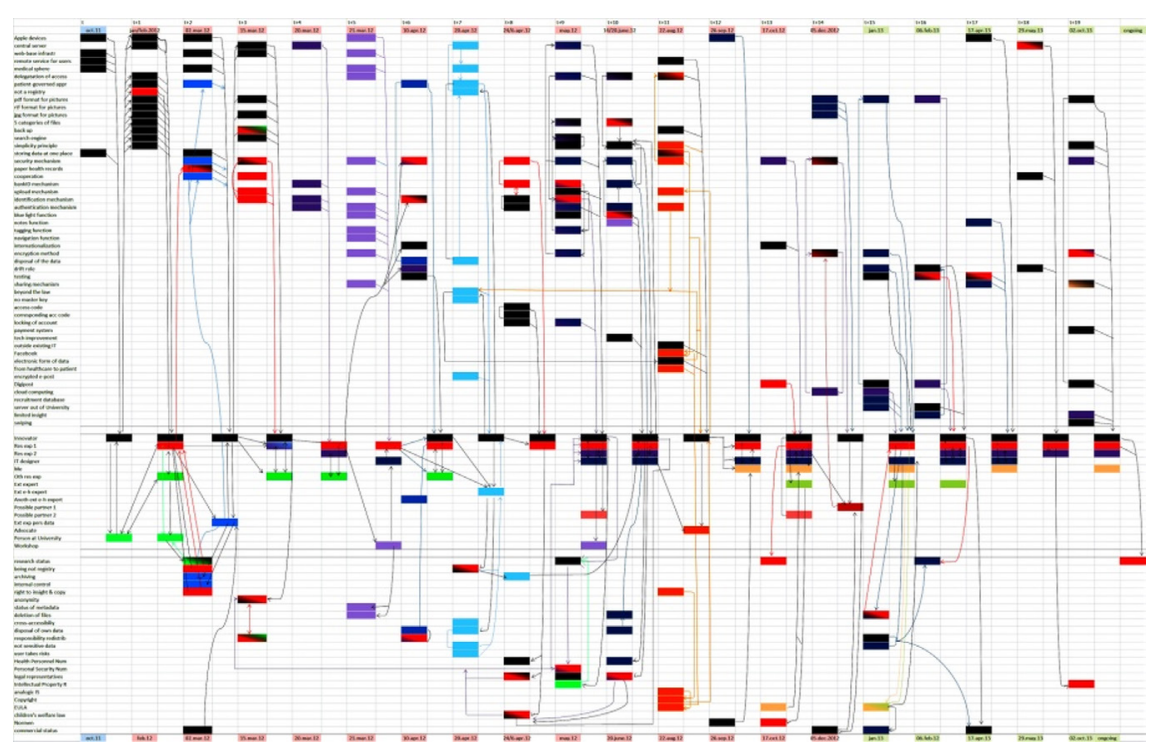

Figure 2: Memory of design work in the first case study.

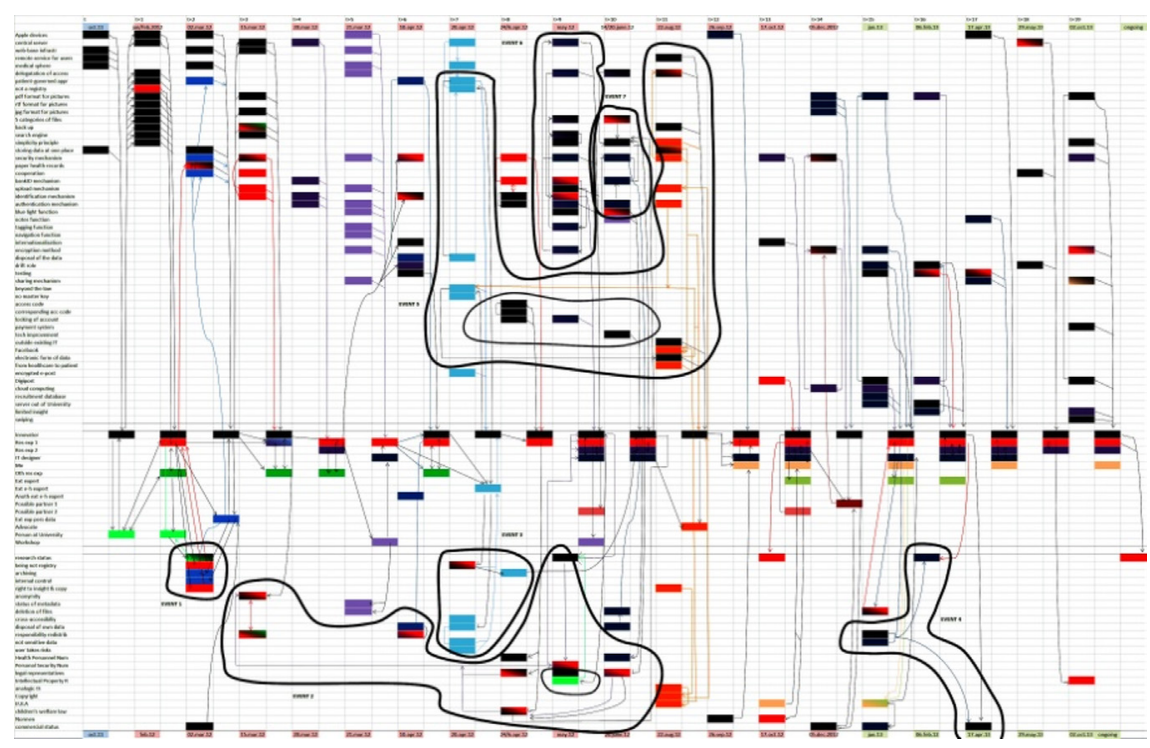

Figure 3: 'Events' in the memory of design work in the first case study.

We may notice that time-tags of the elements inside single 'events' vary, as in the 'events' numbered 2, 3, 4, and 5. For the next visual representation, the elements of 'events' are reorganized in a sequential order of their time-tags. At this step, the researcher drowns on her own memory. It is required to remember empirical data, so that drafting of relations among the elements in the visual representation forms a meaningful storyline consisting of those elements that are found in close 


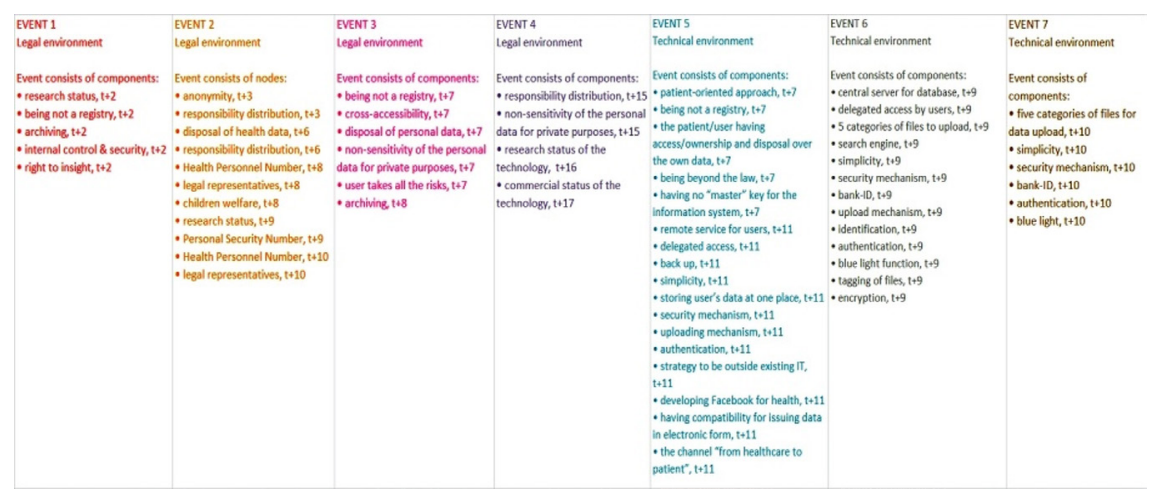

Figure 4: Elements of 'events' in the memory of design work in the first case study.

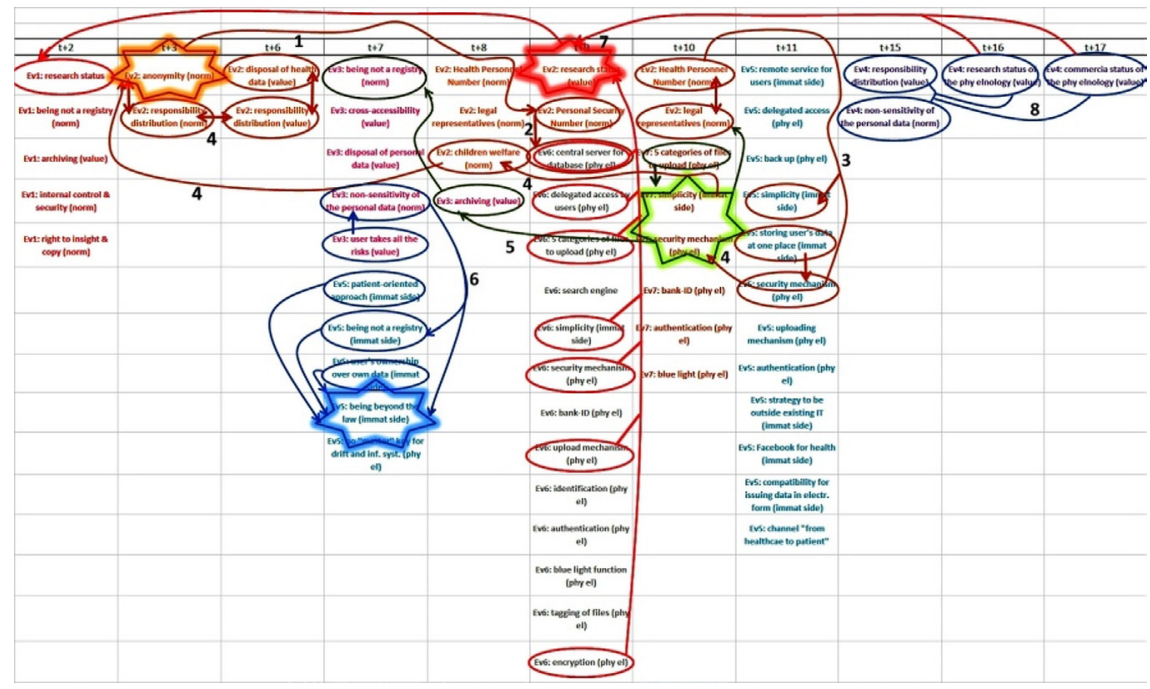

Figure 5: Tracing causal elements among the elements of 'events' in the first case.

proximity. While doing this, we shall keep in mind that building a meaningful story from the available elements implies finding logic first within one 'event' in different time-tags, and then, when the logic seems to fade, among the elements of different 'events' within the same time-tags (Fig. 5).

For example, if for the 'disposal of health data' the issue of 'redistribution of responsibility' among the users of HealthBook was raised, then 'anonymity' of the users that is possible within the concept of patient-ownership of health data emerged as opposite (1), but not contradictory to identification. Identification tends to include in Norway 'Personal Security Number' implying 'central server'; it stores the patient data accessible via identification mechanisms (2); authentication that is secondary to identification happens via 'Health Personnel Number', a property of 'security mechanism' adapted specifically to HealthBook for its 'archiving' purpose, which puts the technology into a possible legal status of 'health registry', something that the technology concept wants to avoid (3). The same logic is applied further. 
In this multi-step, non-linear qualitative analysis, the elements collecting more than three arrows are marked as stars - they are causal elements. These are 'anonymity', 'simplicity and 'security' considered together, 'being beyond the law' and 'research status' of HealthBook. The use of interview data as narrative acts helps the researcher to retrieve further details regarding key reasoning and concerns $[12,13]$ in the decisions taken on technologic implications of these elements in the design work. Since the professional meanings of the people vary depending on their experience and impression from the design work, the researcher is able to retrieve rich contextual information [10] to make conclusions about the attraction in the legal environment to the final decision-making via the causal elements as the most sensitive in the design work.

From the narrative data, it was found that the technologic implications to 'anonymity' were stating username and e-mail address of the individual for registration and use of HealthBook that does not have any technologic channel of verification to the user's identity, when the identity could only be disclosed from the shared health data itself. The legal side of this is that law does not impose any duty to design verification mechanisms if the technology has such architectural constitution as HealthBook - the cloud computing model - and, therefore, as the involved in situ designer says, 'the system does not discriminate' its users. This technologic detail is, however, unclear to the users when they create an account and accept the terms and conditions, which raises a legal attraction or concern $[12,13]$ about how much the user shall be informed about the technology.

The second causal element 'simplicity and security' has technical implications in its sharing mechanism that is simple, but implies stating health personnel number, encryption methods, and entrance code generation. Legally speaking, this is not the highest level of security that is supposed to be applied in the Norwegian e-health sector, but HealthBook has a unique security framework and informs the user in the terms and conditions that s/he takes all risks, which is considered as an agreement between the individual and the e-health service provider. This fact raises a legal attraction on the responsibilities of the e-health service provider - do they exist and what are they built upon?

The third causal element is 'being beyond the law', which from the narrative material determines the lack of own database for storing health data in the architecture of HealthBook. This corresponds legally to the lack of duty to internal control and to the architecture not being considered as a health registry. Not being a health registry is indirectly allowed by par. $2 \S 3$ of the Act on Personal Data, which excludes the power of this law and other related laws in case sharing of sensitive personal data takes place for private purposes. The database, which lacks in architecture, indicates a legal attraction relating to the issue on how to define a data controller - one who is responsible for data processing.

The fourth causal element 'research status' determines the technical implication in the form of a server within the cloud computing model of HealthBook with the university possessing it. In legal terms, HealthBook is a research project, whereas in accordance with its concept, it was supposed to be a novel, privately owned 'patient-governed journal' with commercial implementations. 'Research status' raises an attraction on what legal nature patient journal systems may have and what kind of statuses they might balance in between.

Since both of the studied IS exist in the same legal environment - the national legislation of Norway - the researcher may assume that their design works might share attractions. This forms a hypothesis for subsequent steps in the method. However, due to the differences of the cases in their scale and time consumption for design works, the causal elements might unforeseeably differ in forms/shapes as expressed in the documentary data.

In order to test the hypothesis, the same method of finding causal elements and areas of attraction is applied to the second case study, which is a nationwide e-health infrastructure for critical health information. The rules of drawing the memory for the National Core Journal (Fig. 6) are identical to those formulated concerning the memory of HealthBook. 


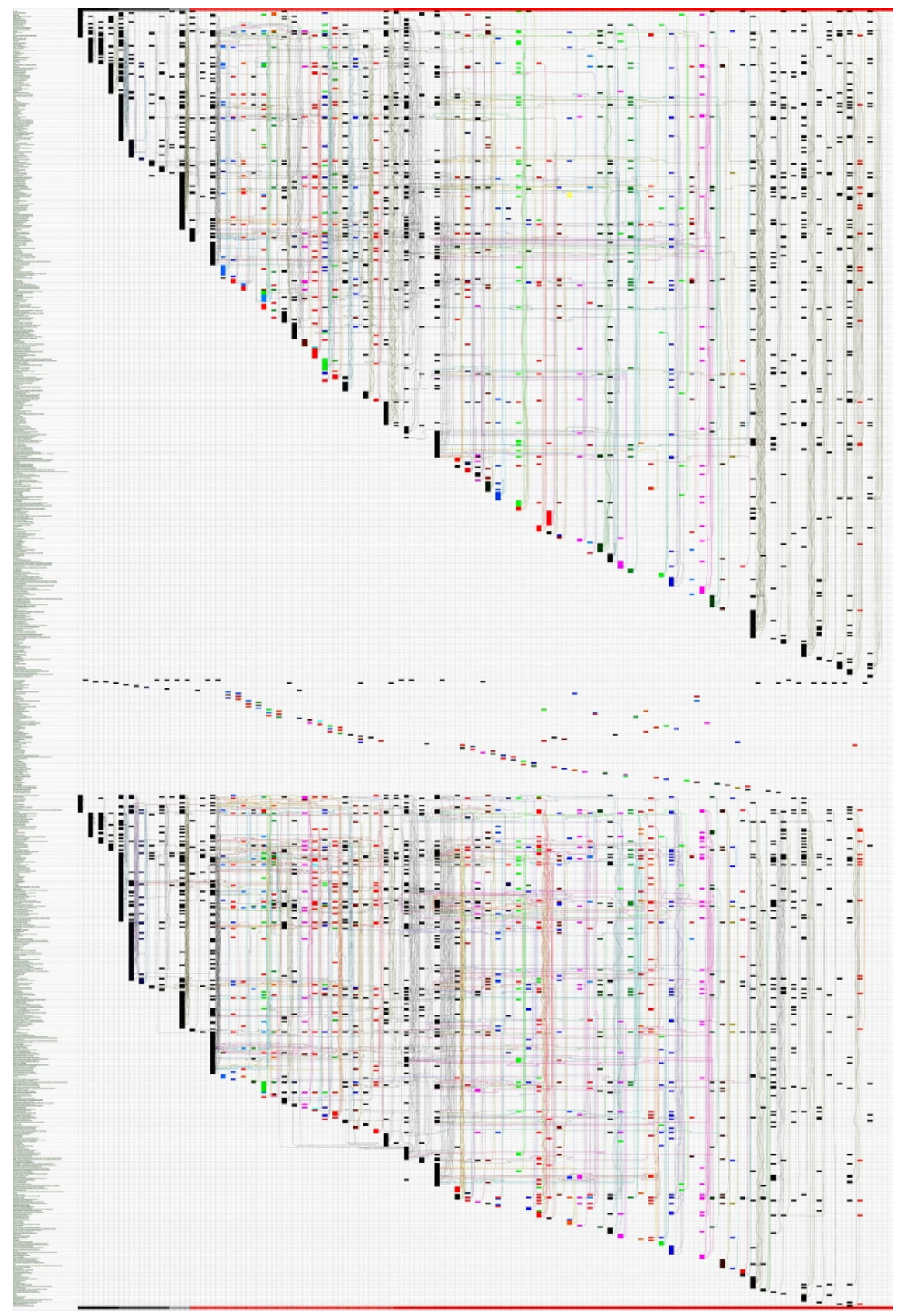

Figure 6: Memory of design work in the second case study.

The only difference is that there is no need to interrelate the technology and law sectors with the sector of actors involved in the design work, because exchange of professional opinions in documentaries took place not at the shared design meetings, but via communication of official documents by deadlines as replies to the previously published reports and legislative proposals. Besides, the 'events' 
of visual complexities are only to be found in the sectors of technology (on the top) and law (on the bottom) in separation, as it was done for Fig. 3. Consequently, their elements are to be interconnected in the subsequent step of the story-building by the researcher in accordance with the rules prescribed for Fig. 5. That step would reduce 'noise' of multiple voices from 77 people/agencies in the design work on the National Core Journal toward 451 elements of technology and 346 elements of law.

In the provided visual representation of memory in the second case study, we can visually notice 14 complexities, or 'events', for further non-linear analysis. Due to limitations of the page format for writing this article, the figure with the marked 'events' is not provided, but it is necessary to hint that the 'events' have horizontal positioning and are highly interconnected with each other. The researcher would notice that while unraveling their elements via links and organizing them in columns for the second case study in the same way as it was done for the first case study (Fig. 4). The rule to unravel the 'events' is based on tracing elements with a link of a color other than their own. If an element belongs to more than one 'event' due to its high interconnectivity with the other 'events', then the element is considered belonging to the 'event' where it was discovered first. The visual representation for history-building and finding the causal elements in the second case is shown in Fig. 7.

According to the story-building conducted among the elements, as based on the rules to Fig. 5, Fig. 7 illustrates that the causal elements in the design work on the National Core Journal are 'patient consent', 'centralization of information', 'synchronization', 'control over data by patient' (met two times), 'sensitivity of health data' (met two times), and 'automatic update'.

In terms of 'patient consent', its technological implication is the mechanism of access to health data in the National Core Journal designed to allow insight into it on having registered a consent given to health personnel by a patient. However, as it comes from the narrative data with the leading in situ designer of this technology, to have patient consent as the only legal ground 'would make the

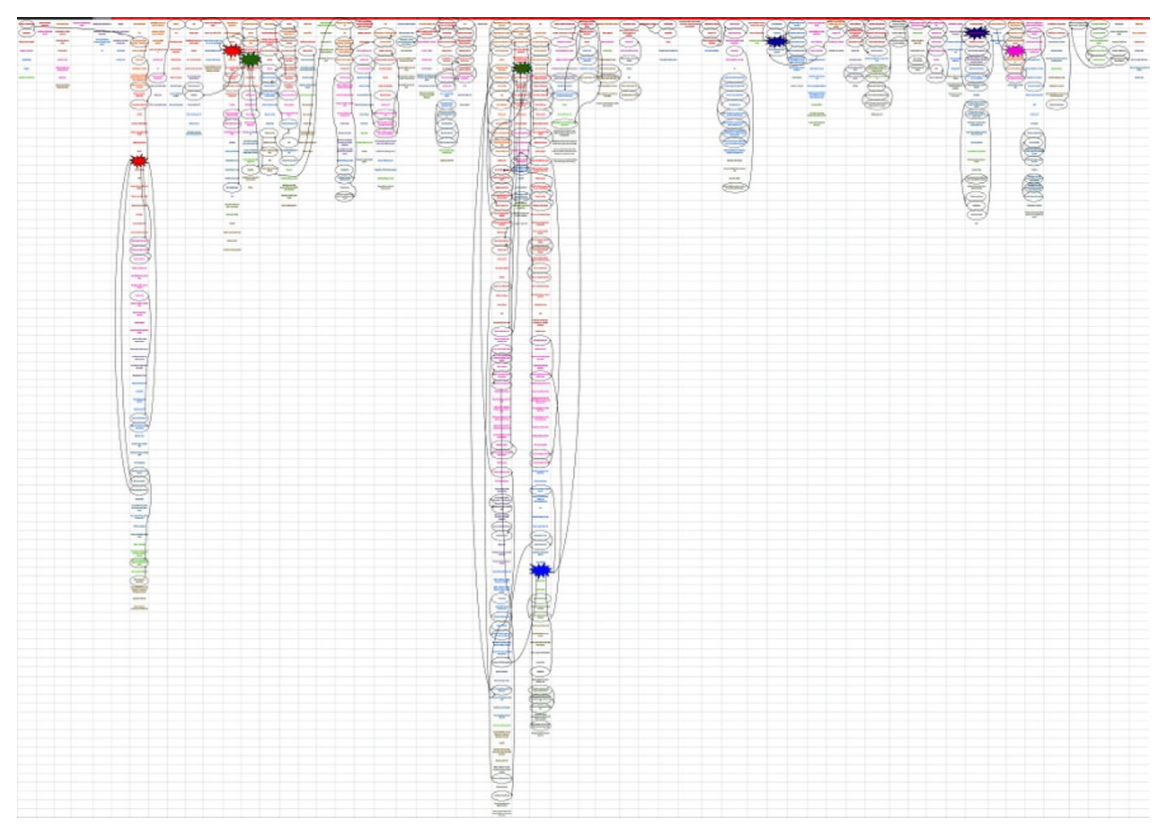

Figure 7: Tracing causal elements among the elements of 'events' in the second case 
National Core Journal impossible' as in all countries where access to e-health infrastructures is based on patient consent. Therefore, the legal side of the access to the National Core Journal is also the right of patient to reserve him/herself from this IT solution, what would mean risks of wrong healthcare provision, injuries, or death in case of unplanned hospitalization. Before using the right to reserve against the National Core Journal, the patient shall be completely informed about the full set of services that this information infrastructure provides. To be informed about the right of reservation against the National Core Journal means also being informed about consent giving. As the designer claims, having the user informed is a difficult legal issue in case of e-health service provision based on agreements with private e-service providers. This finding is shared with the attraction for 'anonymity' in HealthBook.

'Centralization of information' as a causal element implies storing vital health data at one place for sharing cross-over health organizations. As the ex situ expert of the design work mentions in the narrative empirics, the National Core Journal became 'an alternative solution toward electronic cards of health personnel sharing patient data for treatment purposes'. Legally speaking, this intention led to creation of the norm $\S 6 \mathrm{~d}$ in the renewed Act on Health Registries and migration of its $\S 13$ on data sharing only within one organization to the new $\S 19$ on cross-organizational health data sharing in the Act on Patient Journals. Although the National Core Journal is named so, it is not a conventional patient journal system; it is 'an addition to it' and a health registry, but not under the main regulation by the Act of Health Registries. Balancing between two legal realms make the National Core Journal share the attraction on the unclear nature of patient journal systems, as found via 'research status' of HealthBook.

Although the National Core Journal creates an impression of an integrated infrastructure, it is not so. From the narrative data in situ it follows that serious difficulties have been experienced in the technical integration of IS for the National Core Journal. Electronic patient journals have varied specifications and are delivered by competing providers in Norway, whereas the public-sector Health Personnel Registry and the Population Registry have not been designed for further integration at all. 'Synchronization' as a causal element in the design work implies elaboration of the common requirements to technical functionalities and redistribution of legal responsibilities. The interview data reveals that defining data controllers in the relevant models of infrastructures in the synchronization process is difficult. Thus, the legal attraction on data controllers, as indicated by 'being beyond the law' in the first case, is shared with the design work in the second case as well.

The causal element 'sensitivity of health data' has its technologic implication for hardware in architecture, whereas legally it would relate to the ownership of this equipment and the right to data disposal contained. If the data are stored on a private device of the patient, s/he owns this data and has the right to dispose it for any purpose. If the data are stored on equipment that belongs to anyone else, then the processing of this data - storage and sharing - shall be exercised by the data processor only toward providing proper healthcare to the data owner as guaranteed by the legislation on healthcare. 'Taking measures for proper security mechanisms corresponds the duty of proper healthcare provision', claims an ex situ expert in the design work of the National Core Journal. Thus, the attraction on duties of e-health service providers, as indicated for HealthBook, is not necessarily shared with the National Core Journal case that does not question own duties to the highest level of security. However, this attraction can be shared with another public sector e-health technology - the Personal Health Archive - that is designed for offering services for storing private health data.

The two remaining causal elements 'control over data by patient' and 'automatic update' ground a possible bridge of attractions with other design works on technologies that can be studied further with the method replicated to any third case in the legal environment. 'Control over data by patient' has its technological implications in logging functionality and numerous notifications to the patient on data 
processing. Legally this element implies the right of patient to block own health data against some or all health personnel groups, or block some or all health records, which may indicate the attraction of emerging patient rights to govern information elements. The last, but not the least, 'automatic update' implies collection of critical health data conducted fast and in a structured form which would ensure neutrality of health data interpretation and decreasing probability of fatal medical errors. The possible legal attraction can be relevant to study sanctions on health personnel and responsibility taking for professional errors while using information infrastructures for healthcare provision.

\section{CONCLUSIONS AND FURTHER RESEARCH}

The research presents a method for stepwise qualitative analysis and explanation of the phenomenon of mutual shaping between technologies and law, irrespective of the number of cases and their 'appropriateness'. The method contains not only extraction of wordings from qualitative data, but also meaning-based analytical steps, where narrative analysis is applied for building sets of a story on simultaneous design works within a shared legal environment. If the CAS approach forms a basis for pattern recognition and causality tracing, then the narrative approach contributes to universality of the generated method. This work addresses emerging discussions in Complexity Science on the importance of bottom-up techniques used together with algorithmic, stepwise methods of the highly logic systems thinking. The method generated in this research provides a solution to investigating the wholeness of a space at the edge of the legal sphere of competence and techno-organizational expertise, and reduces the 'noise' of their multiple subjective points of view about what can influence the technology and how the technical solution in its original shape might respond to the law. Furthermore, the method may help analysts to anticipate environmental conditions enabling or constraining technologies that are in the early stages of design work, which might help to prevent cost overruns. Application of the method to empirical, real-world data indicates legal attractors as pointers to relevant legal instabilities that influence strategic decision-making regarding unique combination and modularization of technological elements in unity with ongoing techno-legal co-evolution.

\section{REFERENCES}

[1] Aalberts, B.P. \& van der Hof, S., Digital signature blindness: analysis of legislative approaches toward electronic authentication, Tilburg, November 1999, online publication, http://heinonline.org/, pp. 2-72, 1999.

[2] Rzevski, G. \& Skobelev, P. Managing Complexity, WIT Press: Ashurst, 2014.

[3] Koniaris, M., Anagnostopoulos I. \& Vassiliou, Y., Network Analysis in the Legal Domain: A complex model for European Union legal sources. Physics and Society, Cornell University Library. Online publication, http://arxiv.org/abs/1501.05237

[4] Knackstedt, R., Eggert, M., Heddier, M., Chasin, F., \& Becker, J., The relationship of IS and law: the perspective of and implications for IS research. ECIS 2013 Proceedings, paper 18, 2013.

[5] Waldrop, M.M., Complexity: the Emerging Science at the Edge of Order and Chaos. Simon \& Schuster Paperbacks: New York, 1992.

[6] Kauffman, S.A. Investigations, Oxford University Press: New York, 2000.

[7] Feng, P. \& Feenberg, A., Thinking about design: critical theory of technology and the design process. Philosophy and Design: From Engineering to Architecture, ed. P.E. Vermaas, P. Kroes, A. Light, \& S.A. Moore, Springer Science Business Media B.V. pp. 105-118, 2008.

[8] Holland, J.H., Adaptation in Natural and Artificial Systems: an Introductory Analysis with Applications to Biology, Control, and Artificial Intelligence, Massachusetts Institute of Technology: Massachusetts, 1992. 
[9] Wegner, D.M., A computer network model of human transactive memory. Social Cognition, 13(3), pp. 319-339, 1995. doi: http://dx.doi.org/10.1521/soco.1995.13.3.319

[10] Tsoukas, H. \& Hatch, M.J., Complex thinking, complex practice: the case for a narrative approach to organizational complexity. Human Relations, 54, pp. 979-1013, 2001. doi: http:// dx.doi.org/10.1177/0018726701548001

[11] Kirsh, D. Thinking with external representations, AI \& Society, 25, pp. 441-454, 2010. doi: http://dx.doi.org/10.1007/s00146-010-0272-8

[12] Luhman, J.T. \& Boje, D.M., What is complexity science? a possible answer from narrative research. Emergence, 3(1), pp. 158-167, 2001. doi: http://dx.doi.org/10.1207/S15327000 EM0301_10

[13] Byrne, D. \& Callaghan, G. Complexity theory and the Social sciences: the state of the art, Routledge: London, New York, 2014. 